\title{
Experimental Analysis of Tensile Mechanical Properties of Sprayed FRP
}

\author{
Zhao Yang and Kun Wu \\ Institute of Urban Construction, Wuhan University of Science and Technology, Wuhan 430065, China \\ Correspondence should be addressed to Zhao Yang; yzwh77@163.com
}

Received 25 July 2016; Revised 26 September 2016; Accepted 27 October 2016

Academic Editor: Kaveh Edalati

Copyright (c) 2016 Z. Yang and K. Wu. This is an open access article distributed under the Creative Commons Attribution License, which permits unrestricted use, distribution, and reproduction in any medium, provided the original work is properly cited.

\begin{abstract}
To study the tensile mechanical properties of sprayed FRP, 13 groups of specimens were tested through uniaxial tensile experiments, being analyzed about stress-strain curve, tensile strength, elastic modulus, breaking elongation, and other mechanical properties. Influencing factors on tensile mechanical properties of sprayed FRP such as fiber type, resin type, fiber volume ratio, fiber length, and composite thickness were studied in the paper too. The results show that both fiber type and resin type have an obvious influence on tensile mechanical properties of sprayed FRP. There will be a specific fiber volume ratio for sprayed FRP to obtain the best tensile mechanical property. The increase of fiber length can lead to better tensile performance, while that of composite thickness results in property degradation. The study can provide reference to popularization and application of sprayed FRP material used in structure reinforcement.
\end{abstract}

\section{Introduction}

Fiber reinforced polymers (FRP) composite materials have been largely used as strengthening and rehabilitation materials for decades in civil engineering. The main forms of these materials are sheet and plate, which are usually externally bonded on the surfaces of structure members. These materials have been proven to be very efficient and convenient in structure strengthening due to their high strength-to-weight ratio with excellent corrosion resistance [1-5]. But there are still some disadvantages in the use of external bonded FRP. The first is that the interfacial debonding between FRP sheet or plate and structure member will occur for the degradation of the bonding quality, which will lead to a premature failure of FRP [6-13]. Although some anchorage devices or mechanical strategies have been studied to delay such kind of debonding failure, this method will make the construction process more difficult. The second is that the ultimate strain of FRP sheets or plates used in structure strengthening cannot reach the ultimate strain in the material tensile test, which means the high strength of FRP sheets or plates cannot be fully used [14-16]. The third is that the external bonding method of FRP sheets or plates will be hardly conducted in some structure members such as beam-column joints, which cannot provide enough flat surfaces for FRP to be pasted continuously and the core areas of which are difficult for such forms of FRP to wrap efficiently [17-22].

To solve the abovementioned problems, the advanced strengthening method using sprayed FRP consisting of randomly oriented reinforcing fibers in a matrix has been suggested. Spray operation was conducted through special equipment (Figure 1). Resins were transferred to a spray gun and sprayed onto the structure surface. Simultaneously, fiber filaments were chopped to short ones in the spray gun and sprayed onto the structure surface, mixed with the resins. Then, the sprayed FRP material can be formed continuously on the structure surface. This kind of FRP has some advantages compared with the external bonded ones. Firstly, when being used on an uneven concrete surface, external bonded FRP needs some material to level the surface, and then the resin is used to bond the FRP and the leveled substrate. Thus, there are resins, leveling materials, and concrete substrate bonded together. This will increase the debonding possibility and make the application process complicated. While using sprayed FRP, the sprayed FRP material can level the surface as well, and thus there are only sprayed materials and concrete substrates that are bonded together and decrease the debonding possibility. 


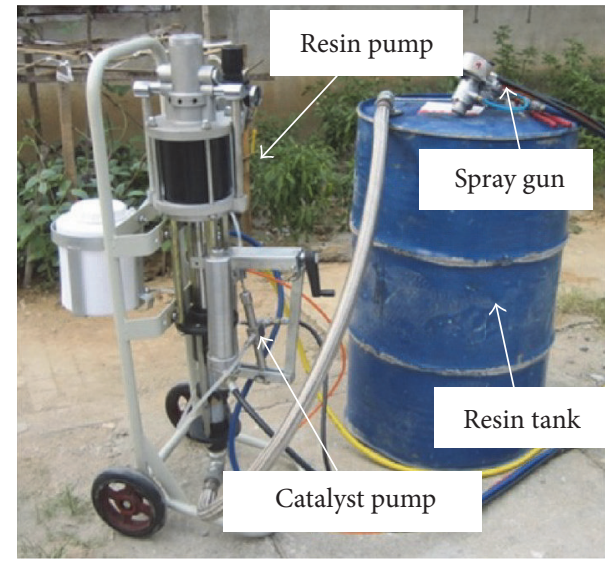

(a) Complete spray equipment

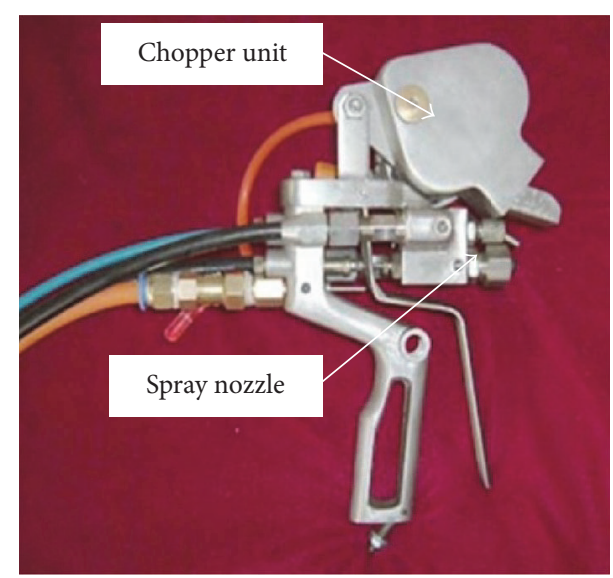

(b) Spray gun

FIGURE 1: Special equipment of sprayed FRP.

The application process is simpler as well without a special leveling process [23]. Secondly, when being used to reinforce a beam-column joint, multilayers of external bonded FRP are required to be bonded on the joint along a different loading direction, which makes the application process much complicated and difficult to assure the construction quality. While using the sprayed FRP, the construction process can be much easier than external bonded method due to the spraying method.

In 2000, sprayed FRP was used for the first time to strengthen the reinforced concrete beams by Boyd. The study showed that the flexural reinforcing effect of sprayed glass FRP was similar to that of FRP fabric wrap or plate bonding onto the beams, while the shear strengthening effect of sprayed FRP was better than other techniques [24]. In 2004, Lee and Hausmann investigated the load capacity, ductility, and energy absorption aspect of RC beams retrofitted with sprayed FRP. The study showed that sprayed FRP was capable of substantially increasing the performance of the beams and was effective in repairing damaged RC beams [25]. Then, Soleimani SM studied sprayed FRP in the shear strengthening and enhancement of impact resistance of reinforced concrete beams [26]. Boyd et al. studied sprayed FRP used in prestressed concrete girders [27]. Ha et al. studied the bond characteristics of sprayed FRP composites bonded to concrete substrate considering various concrete surface conditions [28]. Though the studies above got satisfying results, the use of sprayed FRP for structure strengthening has never been fully investigated.

This paper is written to study the tensile properties and influencing factors of sprayed FRP. A series of specimens of sprayed FRP were tested through tensile experiments. Tensile strength, elastic modulus, breaking elongation, and Poisson ratio of the specimens were studied through the tests. And fiber type, resin type, fiber length, fiber volume ratio, composite thickness, and specimen cutting orientation were compared as influencing factors in the paper too. The results can provide theoretical basis for tensile property calculation and actual application of sprayed FRP.

\section{Tensile Tests}

2.1. Specimens and Experiment Method. In this paper, 3 types of fiber, which are glass fiber, carbon fiber, and basalt fiber, and 2 kinds of resin, which are vinyl ester resin (901) and unsaturated polyester resin (196), were used to make sprayed FRP specimens. The fiber yarns and resins used in the study are shown in Figures 2 and 3. The properties of the fibers and resins are shown in Tables 1 and 2, where the values were obtained from material suppliers. The special equipment used to conduct the spraying process is shown in Figure 1.

The specimens of sprayed FRP were designed in accordance with the shape recommended by Boyd [24] because no specific test method has been published by ASTM so far. However, the dimensions have been changed a little considering the length of the chopped fibers and the fit for the experiment equipment. The detailed dimensions of the actual specimens are shown in Figure 4, in which all dimensions are in millimeters $(\mathrm{mm})$.

The fabrication process of the tensile specimens was divided into several steps. Firstly, a $1000 \mathrm{~mm} \times 800 \mathrm{~mm}$ rectangle glass plate was put on the flat ground with a thin sheet of polyethylene terephthalate paved on it to prevent the adhesion of resin and glass. Then, the chopped fibers and resins were sprayed onto the glass plate to form a sprayed FRP plate. After spraying, a ribbed aluminum compaction roller was used to eliminate the entrapped air voids and make the composite thickness consistent. After hardening, the sprayed FRP plate can be removed from the glass plate and the polyethylene terephthalate sheet can be peeled off. Then, the sprayed FRP plate was cured for seven days in open air at $25^{\circ} \mathrm{C}$. After that, the plate was polished and cut to the designed dimensions. In order to study the isotropic behavior of this sprayed composite, the specimens were cut from the plate in three different orientations, shown in Figure 5.

There are 13 groups of specimens fabricated in the tensile test to study the tensile properties and influencing factors of sprayed FRP material. Each group has 6 specimens to compare the test results and the influencing factors are 
TABLE 1: Properties of fibers.

\begin{tabular}{|c|c|c|c|c|c|}
\hline Type & $\begin{array}{c}\text { Tensile strength, } \\
\sigma(\mathrm{MPa})\end{array}$ & $\begin{array}{c}\text { Elastic modulus, } \\
E(\mathrm{GPa})\end{array}$ & $\begin{array}{c}\text { Breaking elongation, } \\
\varepsilon(\%) \\
\end{array}$ & $\begin{array}{c}\text { Poisson ratio, } \\
\mu\end{array}$ & $\begin{array}{c}\text { Density, } \\
\rho\left(\mathrm{kg} / \mathrm{m}^{3}\right)\end{array}$ \\
\hline Glass fiber $^{\mathrm{a}}$ & 1970 & 79 & 4.8 & 0.20 & 2550 \\
\hline Carbon fiber ${ }^{b}$ & 3500 & 205 & 1.5 & 0.31 & 1750 \\
\hline Basalt fiber ${ }^{c}$ & 2200 & 93 & 2.6 & 0.25 & 2630 \\
\hline
\end{tabular}

${ }^{a}$ Data from Jilin Carbon Co., Ltd., in China.

${ }^{b}$ Data from Zhejiang GBF Basalt Fiber Co., Ltd., in China.

${ }^{\mathrm{c}}$ Data from Jushi Group Co., Ltd., in China.

Table 2: Properties of resins.

\begin{tabular}{|c|c|c|c|c|c|}
\hline Type & $\begin{array}{l}\text { Tensile strength, } \\
\sigma(\mathrm{MPa})\end{array}$ & $\begin{array}{c}\text { Elastic modulus, } \\
E(\mathrm{GPa}) \\
\end{array}$ & $\begin{array}{c}\text { Breaking elongation, } \\
\varepsilon(\%) \\
\end{array}$ & $\begin{array}{c}\text { Poisson ratio, } \\
\mu\end{array}$ & $\begin{array}{l}\text { Density, } \\
\rho\left(\mathrm{kg} / \mathrm{m}^{3}\right)\end{array}$ \\
\hline $901^{\mathrm{a}}$ & 85 & 3.4 & 5.5 & 0.3 & 1050 \\
\hline $196^{\mathrm{b}}$ & 60 & 3.0 & 3.0 & 0.35 & 1230 \\
\hline
\end{tabular}

${ }^{a}$ Data from Swancor Renewable Energy Co., Ltd., in China.

${ }^{b}$ Data from Shenzhen Tonglai Material Technology Co., Ltd., in China.

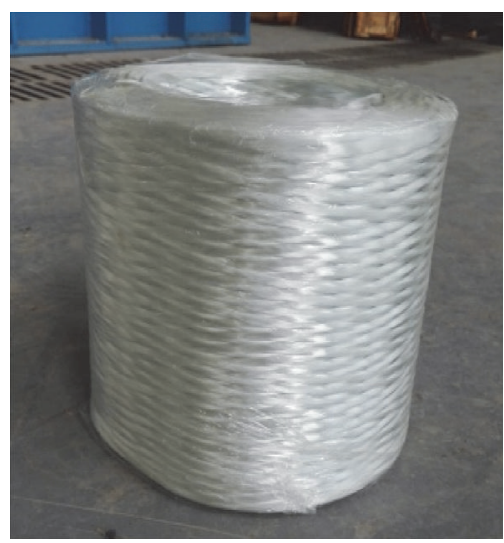

(a) Glass fiber

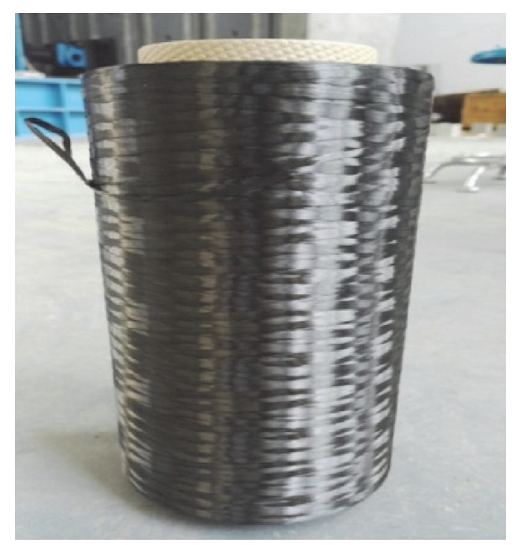

(b) Carbon fiber

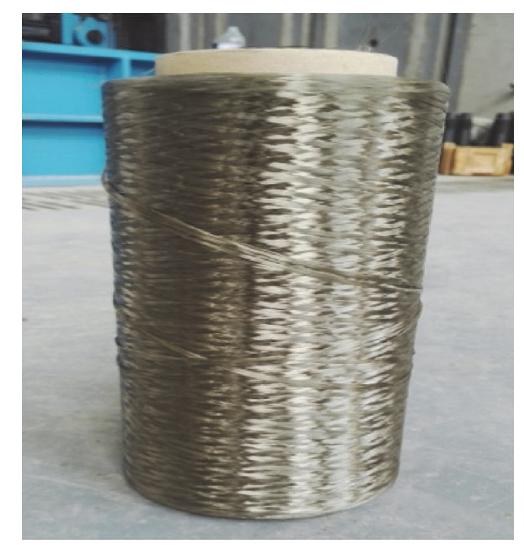

(c) Basalt fiber

FIGURE 2: Fiber yarns used in the experiments.

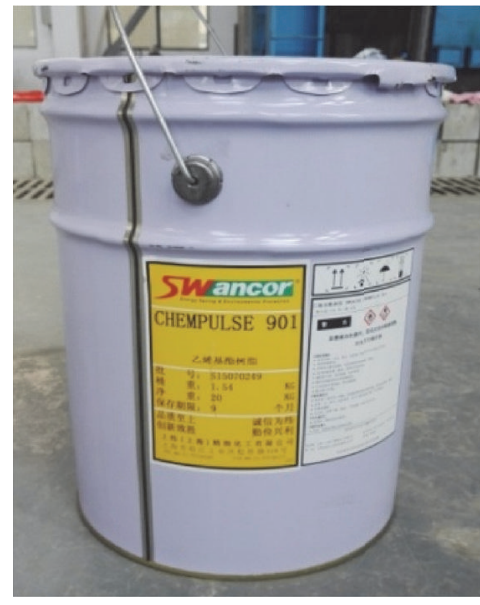

(a) Vinyl ester resin 901

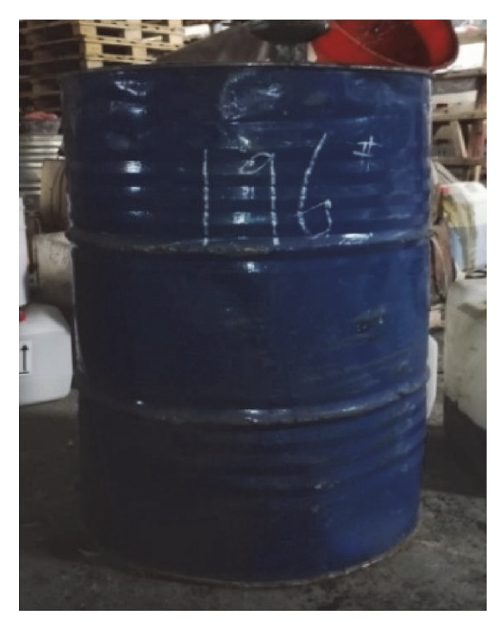

(b) Unsaturated polyester resin 196

FIGURE 3: Resins used in the experiments. 


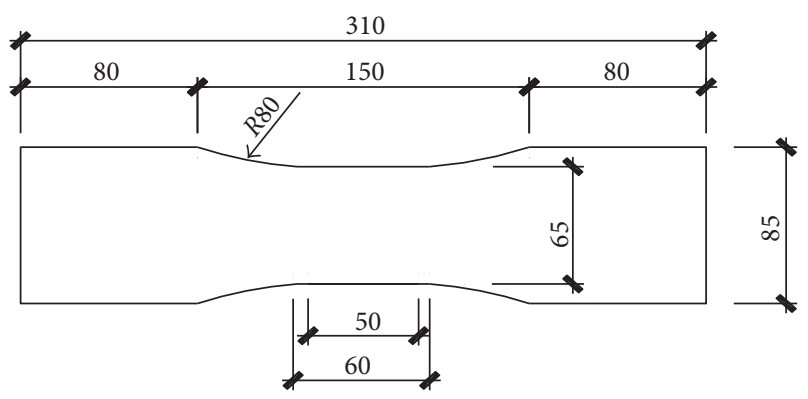

(a) Top view

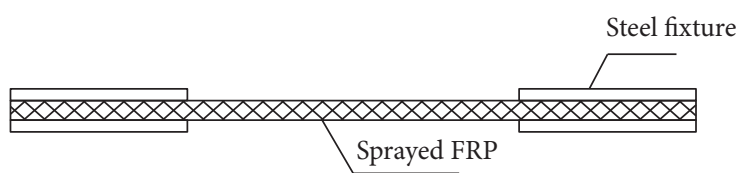

(b) Front view

FIGURE 4: Dimensions of the actual specimens.

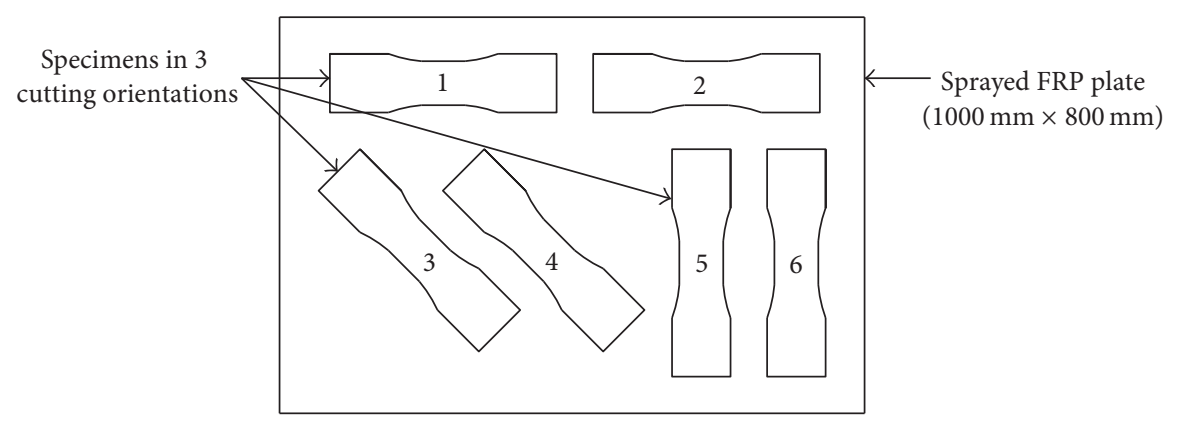

FIgURE 5: Specimen cutting orientation.

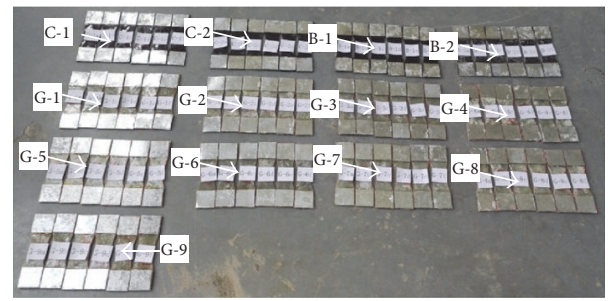

FIGURE 6: 13 groups of specimens.

considered as fiber type, resin type, fiber volume ratio, fiber length, and composite thickness in the paper. The specimen plan is shown in Table 3 and the pictures of the 13 specimen groups are shown in Figure 6.

The composite thickness was controlled by using some plastic plates surrounding the rectangle glass plate on the ground, and the required thickness was marked on the plastic plates, and then the mark could be used to control the composite thickness when spraying. Some concrete blocks were used to fix the plastic plates and prevent deformation. In addition, after cutting the specimens, the thickness of each specimen was measured at both sides of the middle section. The measurement errors were observed to be below 3\% for all specimens, which indicated that the actual thickness met well the designed value.

The fiber length can be easily controlled by adjusting the chopped unit. The fiber volume ratio can be well controlled by adjusting the spraying speed of chopped fibers and resins, respectively, as well. It was observed that error percentages

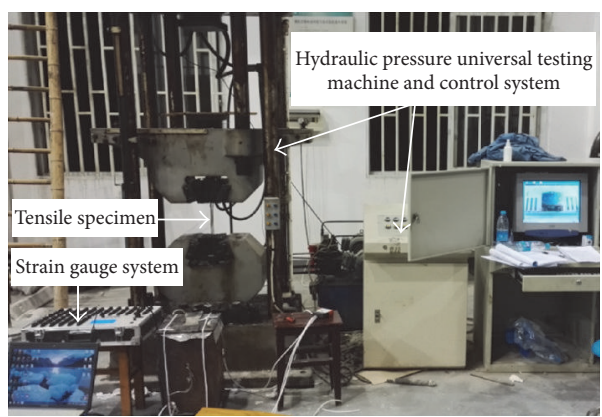

FIGURE 7: Loading and measurement apparatus.

were both lower than $3 \%$, which could meet the design requirements well.

The tensile tests were conducted using a hydraulic pressure universal testing machine, which is shown in Figure 7. In the middle of every tensile specimen, 2 strain gauges in horizontal and vertical direction, respectively, were bonded on the specimen surface to measure the strain of the composite during loading process through a strain gauge system. The loading speed was set to be $2 \mathrm{~mm} / \mathrm{min}$ in accordance with Chinese code GB/T1447 (2005) [29].

\section{Test Results}

3.1. Failure Mode. Through the observation of failure processes of the specimens, all the 13 groups of specimens are similar in failure mode. The failure process can be divided 
TABLE 3: Specimen plan.

\begin{tabular}{|c|c|c|c|c|c|c|}
\hline Group number & Group name & Fiber type & Resin type & Fiber volume ratio & Fiber length $(\mathrm{mm})$ & Composite thickness (mm) \\
\hline 1 & $\mathrm{C}-1$ & Carbon & 901 & $20 \%$ & 30 & 4 \\
\hline 2 & $\mathrm{C}-2$ & Carbon & 196 & $20 \%$ & 30 & 4 \\
\hline 3 & B-1 & Basalt & 901 & $20 \%$ & 30 & 4 \\
\hline 4 & B-2 & Basalt & 196 & $20 \%$ & 30 & 4 \\
\hline 5 & G-1 & Glass & 901 & $20 \%$ & 30 & 4 \\
\hline 6 & G-2 & Glass & 196 & $20 \%$ & 30 & 4 \\
\hline 7 & G-3 & Glass & 901 & $15 \%$ & 30 & 4 \\
\hline 8 & G-4 & Glass & 901 & $25 \%$ & 30 & 4 \\
\hline 9 & G-5 & Glass & 901 & $30 \%$ & 30 & 4 \\
\hline 10 & G-6 & Glass & 901 & $20 \%$ & 15 & 4 \\
\hline 11 & G-7 & Glass & 901 & $20 \%$ & 20 & 4 \\
\hline 12 & G-8 & Glass & 901 & $20 \%$ & 40 & 4 \\
\hline 13 & G-9 & Glass & 901 & $20 \%$ & 30 & 7 \\
\hline
\end{tabular}

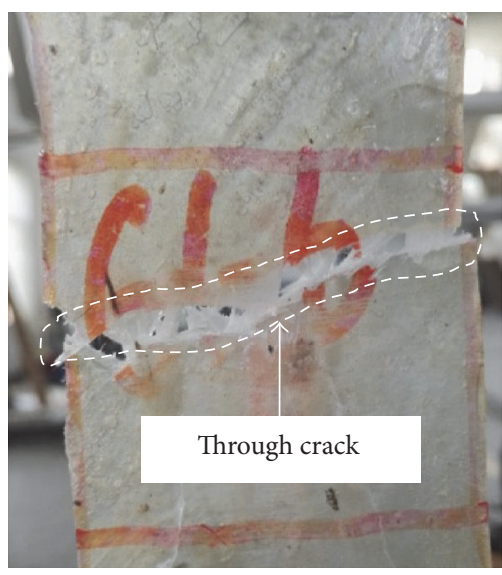

(a) Glass fiber

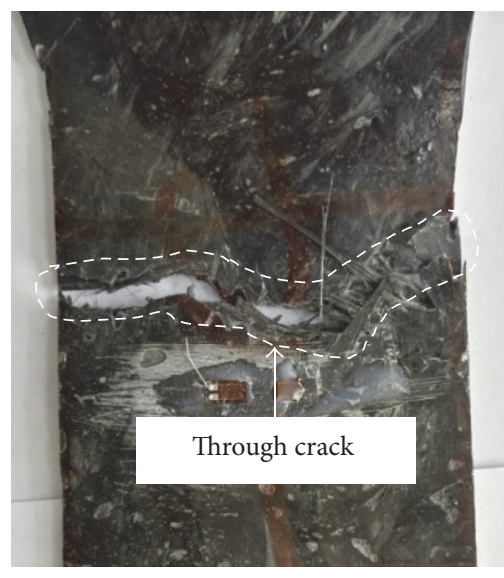

(b) Basalt fiber

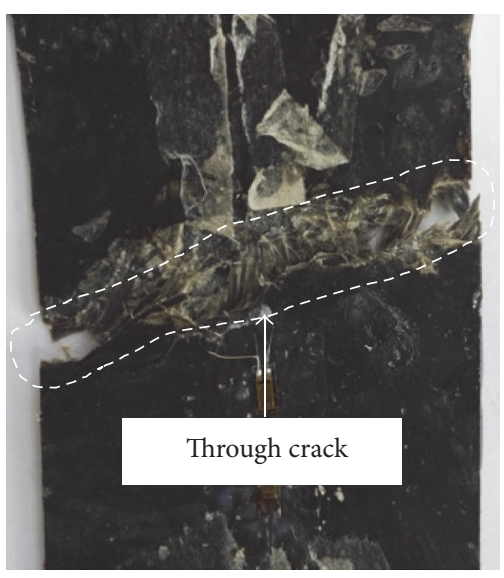

(c) Carbon fiber

FIGURE 8: Through cracks in sprayed FRP specimens of different fiber types.

into 3 stages. In the first stage, the stress in the composite increased quickly with the increase of tensile load, while strain increased slowly. It was observed that there are no signs of cracking or debonding inside the specimens, which always appeared like some small white lines. In the second stage, initial crack could be observed. The strain in composite increased fast, while stress increased slowly. Cracks usually started at the edge of the composite and progressed rapidly to the center. Fracture always began in resin and then debonding occurred between fiber and resin, which made the fiber pull out of the resin and led to crack development. In the third stage, the specimen reached the ultimate load. The stress began to decrease rapidly and strain increased a little. Through cracks were formed (Figure 8) and resulted in a total failure of the specimens. Some fibers along the through cracks were pulled out and some still remained in the resin (Figure 9). There were 3 main modes for the through cracks, which are shown in Figure 10.

3.2. Stress-Strain Relationship. The tensile stress of sprayed FRP can be calculated by dividing the load value by the cross-sectional area of the specimen. The strain of sprayed FRP can be collected automatically by the strain gauge system. Thus, the experimental stress-strain relationship can be achieved. The relationship curves of the 13 groups are very similar and 3 groups of them are shown as examples in Figure 11, from which we can see the 3 stages of the failure process clearly. From Figure 11, we can see that, in the first stage, fibers and resins were working together to bear the tensile load, no cracking or debonding appeared, the strain increased slower than stress, and the first stage of the curve was formed. While the initial cracks appeared, some resins ruptured and debonding between fibers and resins appeared. The deformation of specimens increased more quickly than the loads, and thus the second stage of the curve was formed. When the cracks developed, more and more resins ruptured, the loads were mainly borne by fibers until reaching the bearing capacity, and the ultimate stress of specimens was reached. Then, the stress started to decrease and strain continued to increase. The third stage of the curve was formed. So, the sprayed FRP composites showed a trilinear constitutive behavior. 


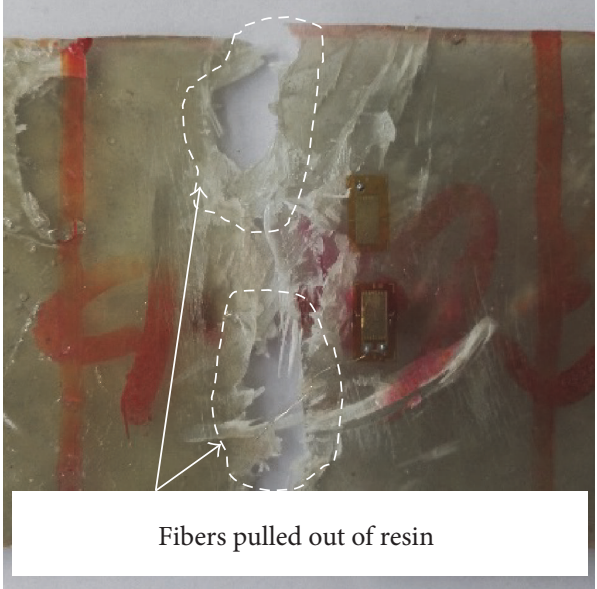

(a)

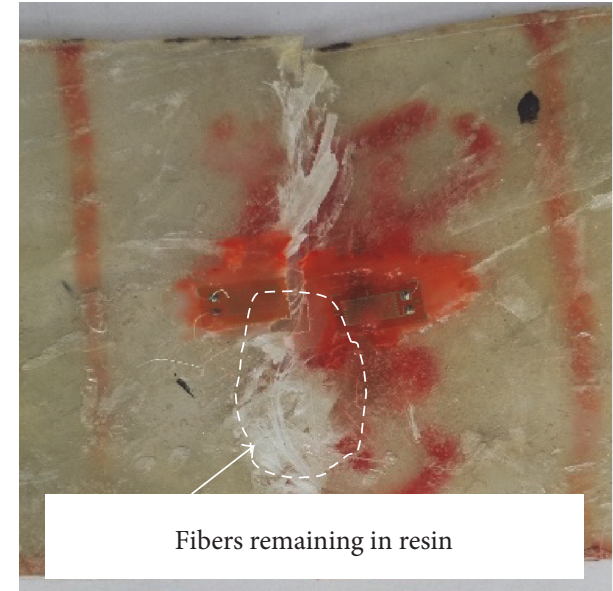

(b)

FIGURE 9: Failure modes of fibers along the through crack.

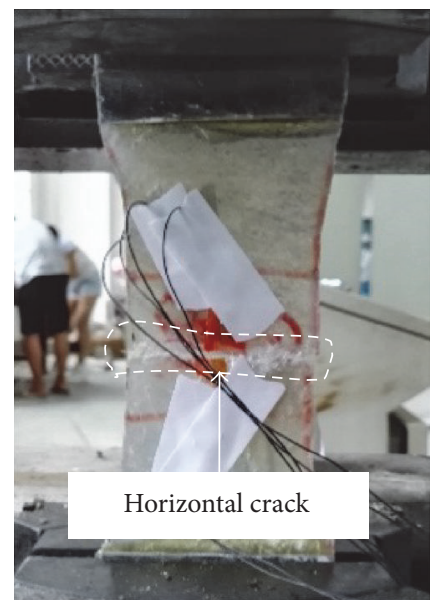

(a)

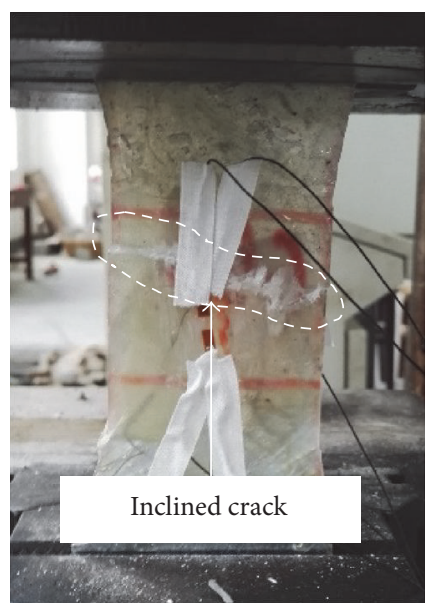

(b)

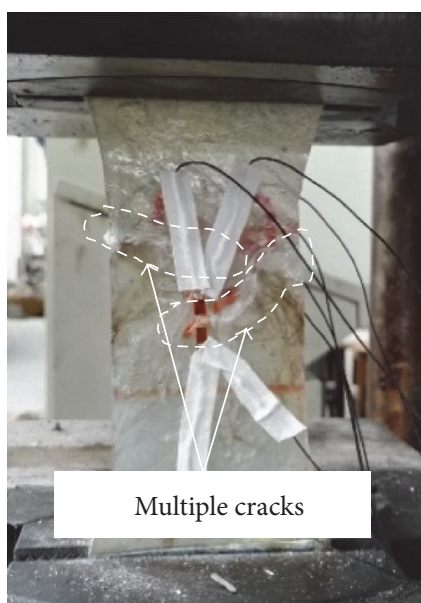

(c)

FIGURE 10: Failure modes of through cracks.

3.3. Tensile Mechanical Properties of Sprayed FRP. Through the data gained from the tensile experiment, several tensile mechanical properties can be achieved using the calculation method recommended in Chinese code GB/T1447 (2005) [29], as shown in Table 4. Due to the difficulty in obtaining the actual initial modulus, the values of elastic modulus reported in Table 4 referred to a secant modulus. The secant endpoints were the endpoints of $50 \mu \varepsilon$ and $40 \%$ of ultimate stress [24]. Note that the values reported in the table represent the averages of all the six specimens in each group and all the error percentages for each group were lower than $3 \%$.

\section{Influencing Factors on Tensile Mechanical Properties of Sprayed FRP}

4.1. Fiber Type. Carbon fiber, glass fiber, and basalt fiber were used, respectively, to make sprayed FRP in the study, and their tensile performances were different. As is shown in Table 3,
C-1, B-1, and G-1 are made of different fibers but the same resin 901 and other influencing factors are all the same. So, these 3 groups can be used to compare the effect of different fiber types using resin 901. In the same way, C-2, B-2, and G-2 are made of different fibers but the same resin 169 and other influencing factors are all the same too. So, these 3 groups can be used to compare the effects of different fiber types using resin 169 .

As is shown in Table 4, C-1 using carbon fiber has the highest strength value of 105.4 MPa, and the strength of $\mathrm{G}^{-}$ 1 using glass fiber is $91.3 \mathrm{MPa}$, while B-1 using basalt fiber has the lowest strength value of $87.2 \mathrm{MPa}$. Among the 3 groups, $\mathrm{C}$ 1 also has the highest tensile elastic modulus value of $49.1 \mathrm{GPa}$, which is $54.4 \%$ higher than G-1 and $74.1 \%$ higher than B-1. As to breaking elongation, the case is just the opposite. B-1 has the highest value of $2.6 \%$, which is $8.3 \%$ higher than G-1 and $23.8 \%$ higher than $\mathrm{C}-1$.

For C-2, B-2, and G-2, the comparative results are similar to the above 3 groups. The strength value of $\mathrm{C}-2$ is the highest 


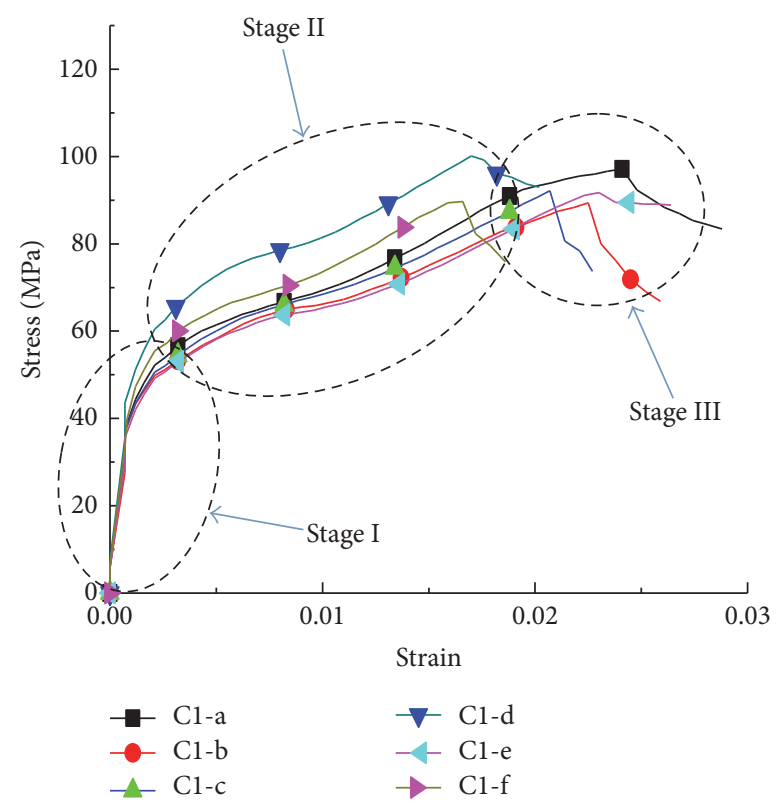

(a) $\mathrm{C}-1$

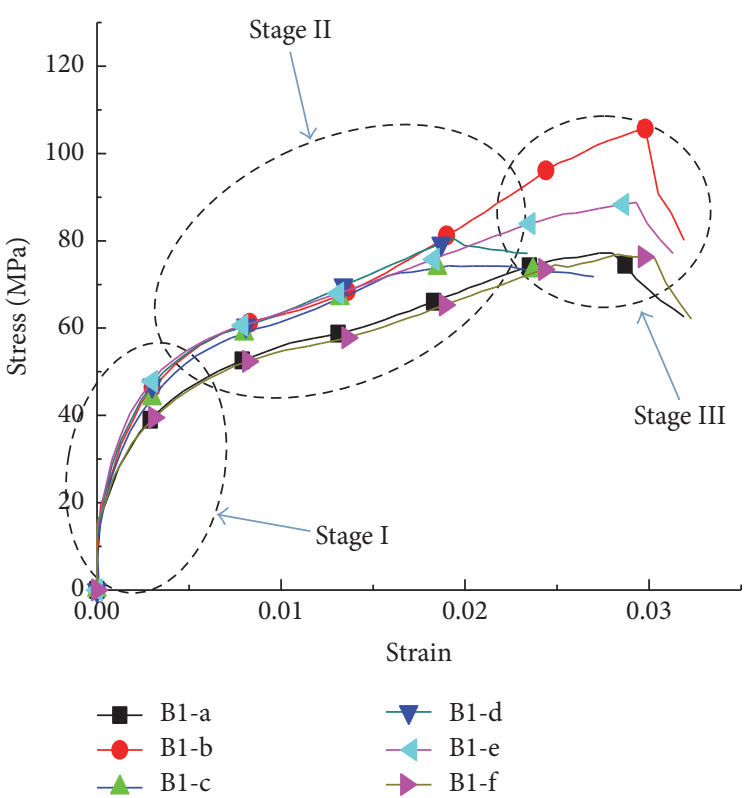

(b) B-1

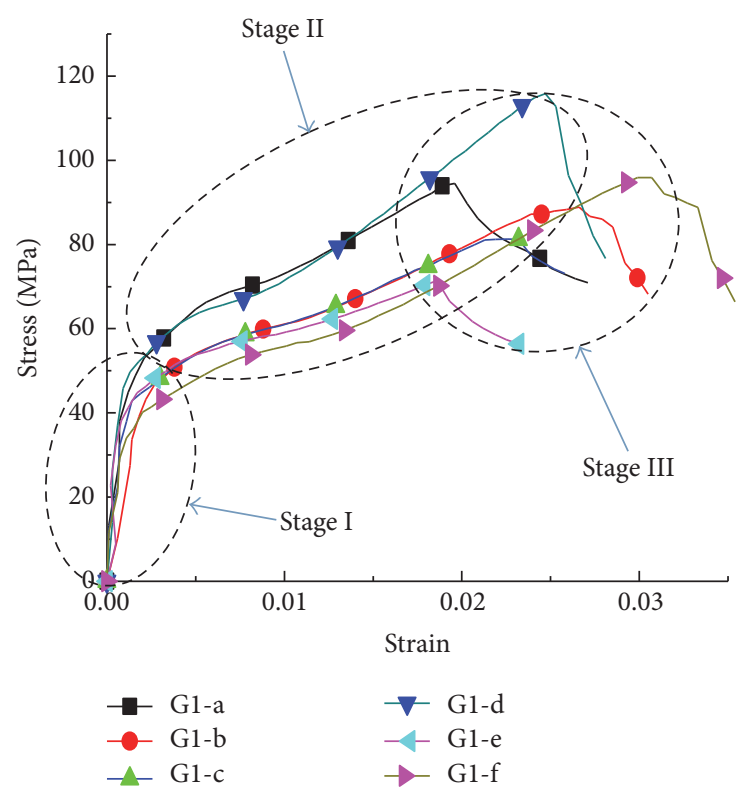

(c) G-1

FIGURE 11: Stress-strain relationship curves.

at $89.3 \mathrm{MPa}$ and G-2 is the lowest at $75.2 \mathrm{MPa}$. The differences in tensile elastic modulus are more significant than the above 3 groups. The value of C-2 is up to $50.7 \mathrm{GPa}, \mathrm{G}-2$ follows by 28.8 GPa, and $\mathrm{B}-2$ is the minimum at $26.1 \mathrm{GPa}$. While the case of breaking elongation is also opposite, B-2 has the highest value of $3.1 \%, \mathrm{G}-2$ follows by $2.4 \%$, and C-2 has the lowest value at $1.9 \%$.

According to the data in Table 4, the effect of different fiber types on tensile properties of sprayed FRP is compared in Figure 12. It can be seen that tensile strength and tensile elastic modulus of sprayed FRP using carbon fiber are higher than those sprayed FRP using glass fiber and basalt fiber, no matter what kind of resin is used. But the breaking elongation of sprayed FRP using carbon fiber is the lowest among the three. These indicate that the tensile performance of sprayed FRP is affected greatly by fiber type and the performance feature of sprayed FRP is always similar to the fiber used, which is in accordance with the conclusion of Lee [30]. It should be noted that the differences in the strength of sprayed FRP using glass and basalt fiber are very small with the maximum value of only $4.9 \%$.

4.2. Resin Type. The effect of resin type on tensile properties of sprayed FRP was studied by comparing C-1 and C-2, B-1 


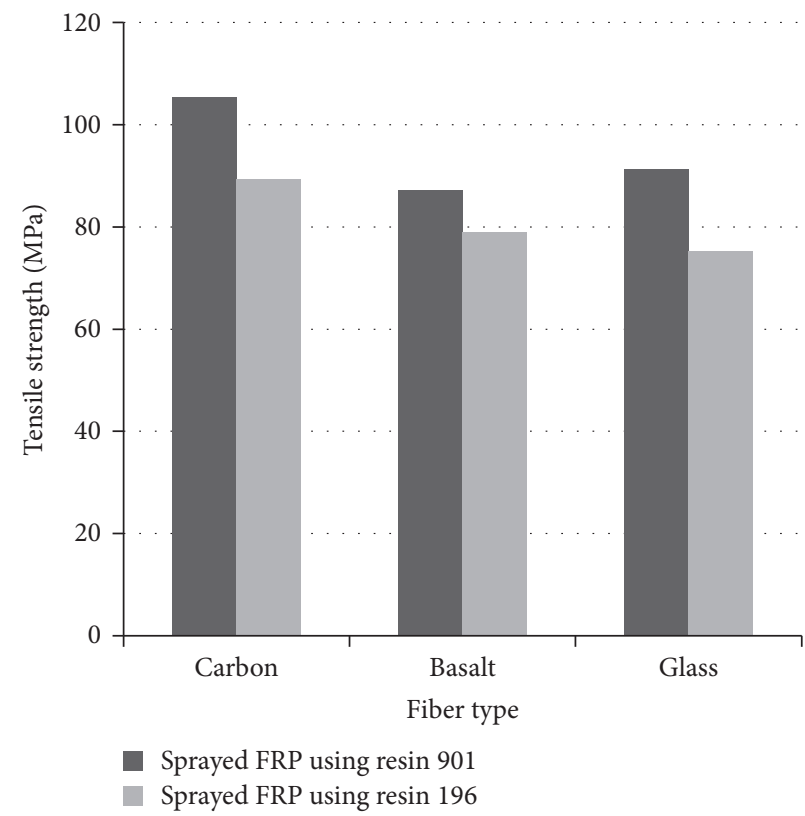

(a) Tensile strength

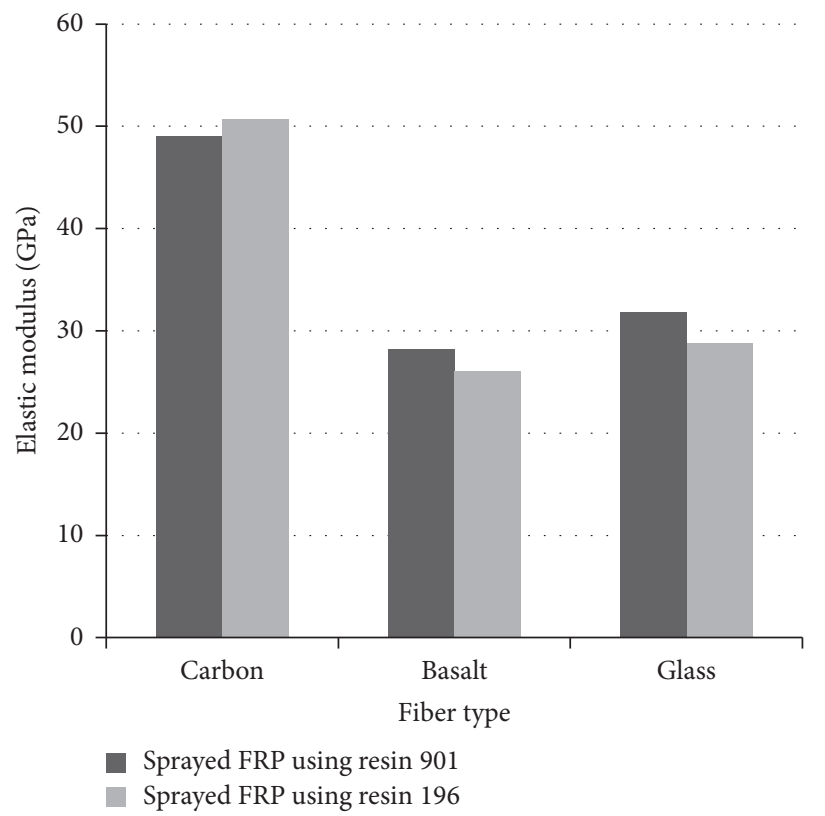

(b) Elastic modulus

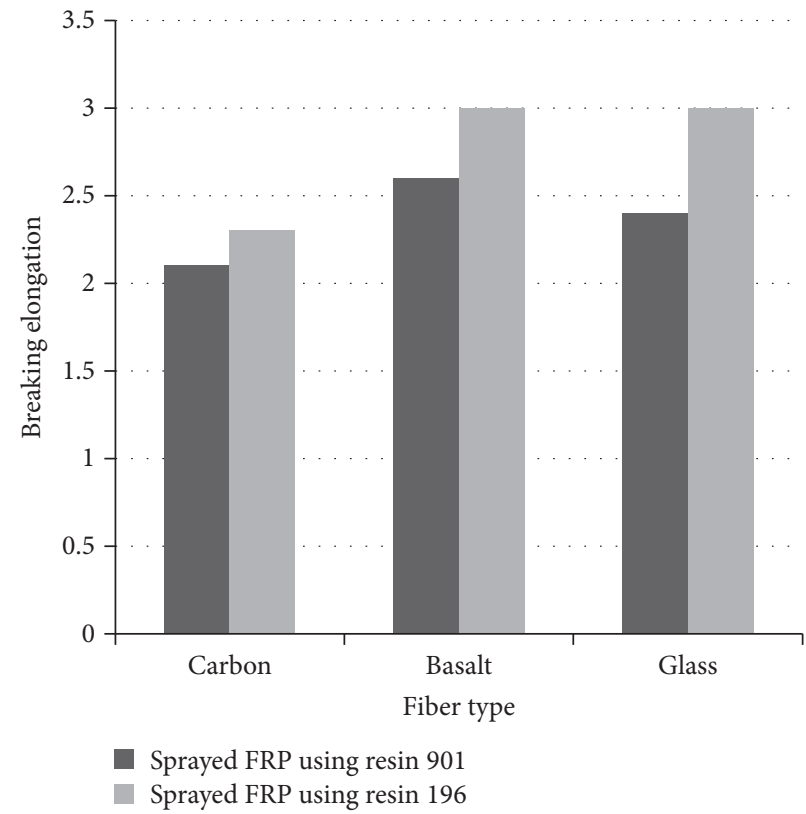

(c) Breaking elongation

FIGURE 12: Comparison of tensile properties of sprayed FRP using different fiber types.

and B-2, and G-1 and G-2, separately, which are different in resin type but the same in all other factors. C-1, B-1, and G1 used vinyl ester resins. C-2, B-2, and G-2 used unsaturated polyester resins. As is shown in Table 4, tensile strength of $\mathrm{C}-1$ is $18.2 \%$ higher than C-2, B-1 is $6.3 \%$ higher than $\mathrm{B}-2$, and G-1 is $21.4 \%$ higher than G-2. Regarding tensile elastic modulus, the values of C-1, G-1, and B-1 are also higher than those of C-2, B-2, and G-2. But, in the comparison of breaking elongation, the cases are different. The value of $\mathrm{C}-1$ is $10.5 \%$ higher than $\mathrm{C}-2$, the value of $\mathrm{B}-1$ is $8.3 \%$ higher than $\mathrm{B}-2$, and the value of G-1 is $20 \%$ lower than G-2.
The above results show that using vinyl ester resin as matrix and adhesive for sprayed FRP can get better tensile mechanical properties generally, which is similar to the result of Lee [30]. But it is worth noting that the breaking elongation of the sprayed FRP using glass fiber will be reduced when using this kind of resin.

4.3. Fiber Volume Ratio. From Table 3, there are 4 groups of specimens used to study the effect of fiber volume ratio on tensile properties of sprayed FRP, which are G-3, G-1, G-4, 


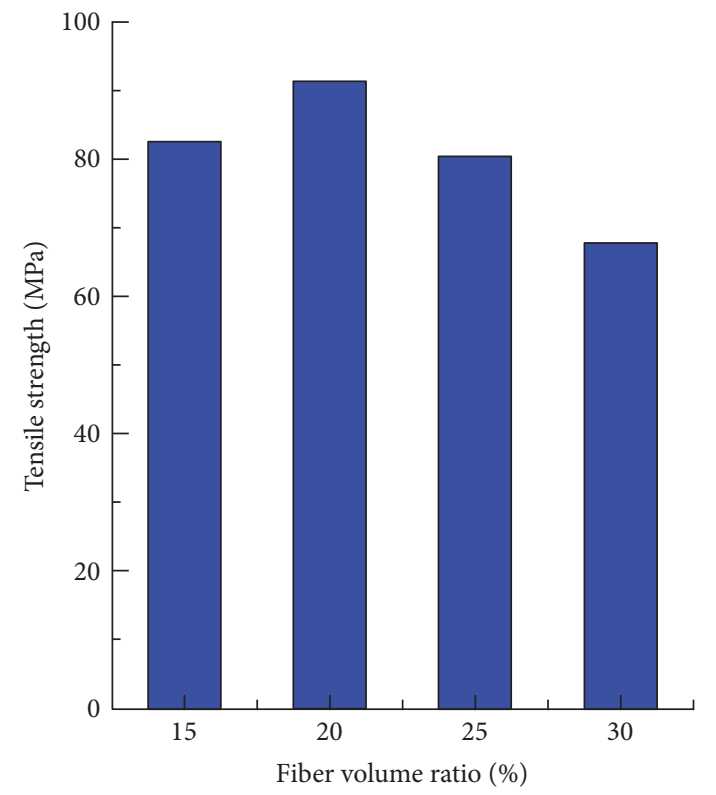

(a) Tensile strength

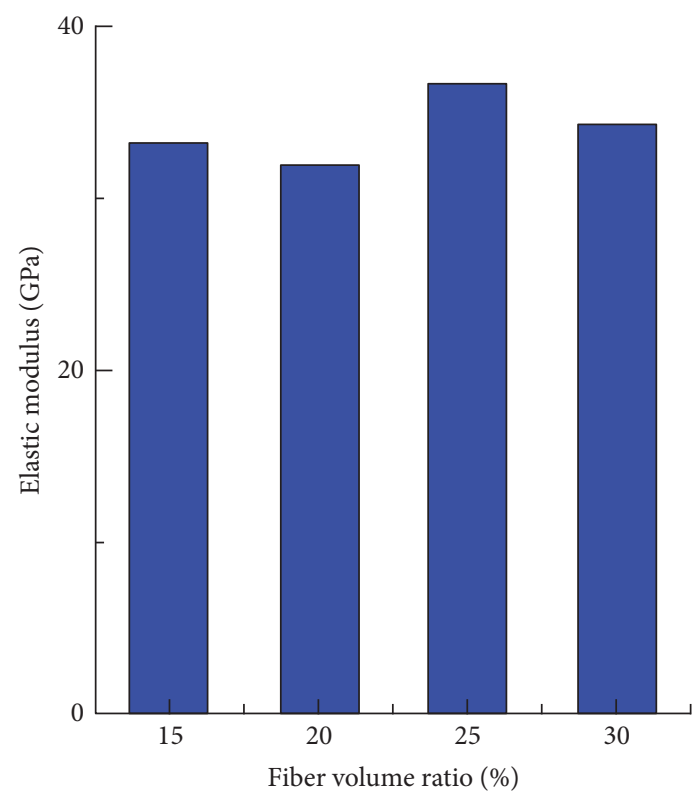

(b) Elastic modulus

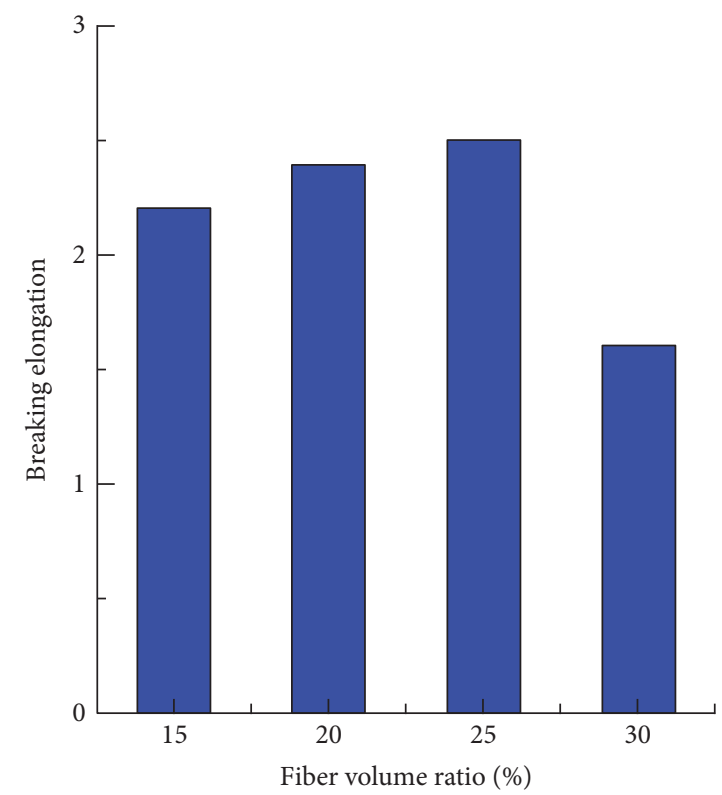

(c) Breaking elongation

FIGURE 13: Comparison of tensile properties of sprayed FRP in different fiber volume ratios.

and G-5, with a fiber volume ratio of $15 \%, 20 \%, 25 \%$, and $30 \%$, respectively.

It can be seen from Table 4 that the tensile strengths of the 4 groups from high to low are G-1, G-3, G-4, and G-5, with a value of $91.3 \mathrm{MPa}, 82.6 \mathrm{MPa}, 80.3 \mathrm{MPa}$, and $67.7 \mathrm{MPa}$, respectively. The highest value of G-1 is $34.9 \%$ higher than the lowest one G-5. As to tensile elastic modulus, the differences of the 4 groups became very small. The differences between G- 4 with the highest value and the other 3 groups ranged from $6.7 \%$ to $15.4 \%$. In the case of breaking elongation, the highest value comes from G-4 too, which is $56.3 \%$ higher than that of G-5 with the lowest value.
From the data in Table 4, Figure 13 was drawn to compare the effects of different fiber volume ratios on tensile properties of sprayed FRP. It shows that there will be a specific value of fiber volume ratio that can lead to a maximum value of a tensile property. And when the ratio is lower than the specific value, the tensile property value will increase with the increase of volume ratio. While the fiber volume ratio is higher than the specific value, the case is just the opposite. This is because when the fiber volume ratio is low, there will be more fibers participating in bearing tensile stress with the increase of ratio, which results in an increase of tensile capacity of sprayed FRP. While the ratio is higher than the 
TABLE 4: Summary of tensile properties of sprayed FRP.

\begin{tabular}{|c|c|c|c|c|c|}
\hline Group number & $\begin{array}{l}\text { Group } \\
\text { name }\end{array}$ & $\begin{array}{l}\text { Tensile strength, } \sigma \\
(\mathrm{MPa})\end{array}$ & $\begin{array}{c}\text { Elastic modulus, } E \\
(\mathrm{GPa})\end{array}$ & $\begin{array}{c}\text { Breaking elongation } \\
(\%)\end{array}$ & Poisson ratio, $\mu$ \\
\hline 1 & $\mathrm{C}-1$ & 105.4 & 49.1 & 2.1 & 0.30 \\
\hline 2 & C-2 & 89.3 & 50.7 & 2.3 & 0.31 \\
\hline 3 & B-1 & 87.2 & 28.2 & 2.6 & 0.22 \\
\hline 4 & B-2 & 78.9 & 26.1 & 3.0 & 0.25 \\
\hline 5 & G-1 & 91.3 & 31.8 & 2.4 & 0.24 \\
\hline 6 & G-2 & 75.2 & 28.8 & 3.0 & 0.26 \\
\hline 7 & G-3 & 82.6 & 33.3 & 2.2 & 0.22 \\
\hline 8 & G-4 & 80.3 & 36.7 & 2.5 & 0.25 \\
\hline 9 & G-5 & 67.7 & 34.4 & 1.6 & 0.24 \\
\hline 10 & G-6 & 78.1 & 27.1 & 2.1 & 0.21 \\
\hline 11 & G-7 & 87.1 & 30.8 & 2.2 & 0.26 \\
\hline 12 & G-8 & 101.2 & 38.3 & 2.4 & 0.24 \\
\hline 13 & G-9 & 66.1 & 23.7 & 1.9 & 0.24 \\
\hline
\end{tabular}

specific value, fibers will be too much, and thus the resin around the fibers will not be enough to transfer and balance the stress of fibers effectively, which will lead to partial failure in some fibers or resins earlier and make the tensile property reduced.

4.4. Fiber Length. From Table 3, there are 4 groups of specimens used to study the effect of fiber length on tensile properties of sprayed FRP, which are G-6, G-7, G-1, and G8 , with a fiber length of $15 \mathrm{~mm}, 20 \mathrm{~mm}, 30 \mathrm{~mm}$, and $40 \mathrm{~mm}$, respectively.

From Table 4, tensile strengths of the 4 groups from high to low are G-8, G-1, G-7, and G-6, with a value of $101.2 \mathrm{MPa}$, 91.3 $\mathrm{MPa}$, 87.1 $\mathrm{MPa}$, and 78.1 $\mathrm{MPa}$, respectively. For tensile elastic modulus, the highest value also belongs to G-8, which is $41.3 \%$ higher than the lowest one G-6. As to breaking elongation, the highest value is $2.4 \%$ which comes from $\mathrm{G}$ 8 and G-1, followed by $2.2 \%$ from G-7, and the lowest one is 2.1\% from G-6.

The relationship curves of tensile stress and strain of the 4 groups are compared in Figure 14. It shows that the longer fiber can bear more stress than the shorter ones when tensile strain is the same, which is in accordance with Boyd's result [24]. This can be explained as the longer length fibers can obtain a larger bonding area with resins, and thus the bonding effect will be better than the shorter ones, which can lead to better tensile properties.

4.5. Composite Thickness. From Table 3, there are 2 groups of specimens used to study the effect of composite thickness on tensile properties of sprayed FRP, which are G-1 with a $4 \mathrm{~mm}$ thickness and G-9 with a $7 \mathrm{~mm}$ thickness.

From Table 4, the tensile strength of G-1 is $91.3 \mathrm{MPa}$ and that of G-9 is $66.1 \mathrm{MPa}$. The tensile elastic modulus of G1 is $31.8 \mathrm{GPa}$ and that of G-9 is $23.7 \mathrm{GPa}$. As to breaking elongation, G-1 is $2.4 \%$ and G-9 is $1.9 \%$. It is shown that tensile strength, elastic modulus, and breaking elongation will all

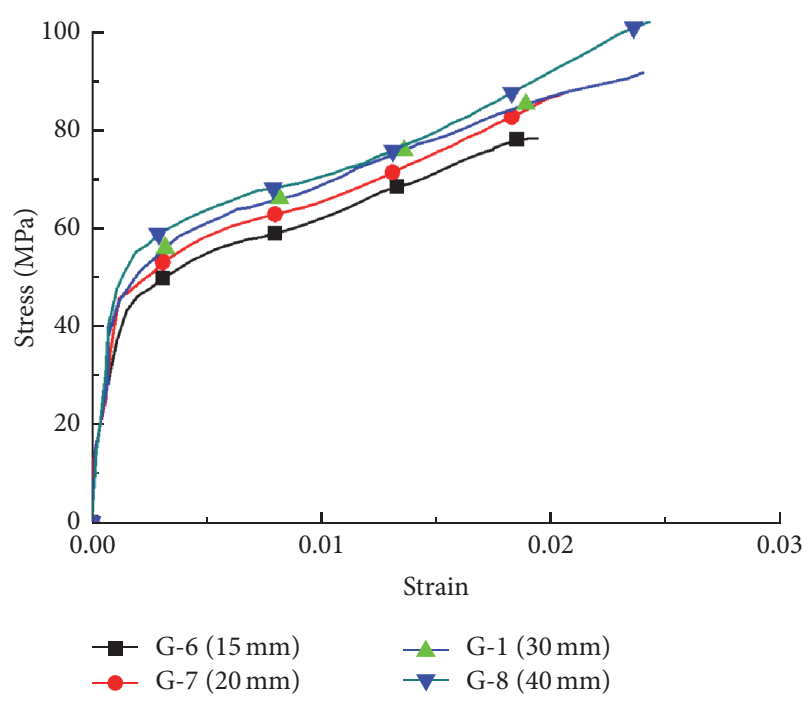

FIGURE 14: Comparison of stress-strain curves of sprayed FRP with different fiber lengths.

be reduced with the increase of composite thickness. This is because the initial defects in sprayed FRP materials will become more with the increase of composite thickness, which will lead to degradation of tensile properties.

4.6. Specimen Cutting Orientation. All the specimens were cut from the sprayed FRP plate in three different orientations, which is shown in Figure 5. As mentioned before, all the error percentages for each group in Table 4 were lower than $3 \%$, so there was not any obvious difference in tensile properties of the specimens in different cutting orientations in each group. Comparing the Poisson ratios of the 13 groups of specimens in Table 4 , most values are close to the average value of 0.25 . The above results indicate that the sprayed FRP composite can be seen as an isotropic material. 


\section{Summary and Conclusions}

This paper has studied the tensile properties of sprayed FRP through tensile experiments of 13 groups of specimens, which include tensile strength, elastic modulus, breaking elongation, and Poisson ratio. The effects of several influencing factors are compared too. The following conclusions are drawn:

(1) Fiber type has an important influence on tensile properties of sprayed FRP material. The composites made of carbon fiber have higher values of tensile strength and elastic modulus than those made of glass fiber or basalt fiber, while the breaking elongation of carbon fiber composites is lower. The results equate the tensile properties of the three types of fibers.

(2) The test results of the 2 resins used in this paper show that using vinyl ester resins to make sprayed FRP can get better tensile properties than using unsaturated polyester resins generally. But the breaking elongation of glass fiber specimens using vinyl ester resins is lower compared with using unsaturated polyester resin.

(3) There will be a specific value of fiber volume ratio for every kind of sprayed FRP material, which can lead to the highest value of a tensile property. Less or more than this volume ratio can make the tensile property of this sprayed FRP degrade.

(4) The increase of fiber length can make the tensile properties of sprayed FRP better, while the increase of composite thickness will lead to property degradation.

(5) Cutting orientation of sprayed FRP specimens has no obvious influence on tensile properties and the Poisson ratios are almost the same for all the specimens, which shows that sprayed FRP can be looked at as a kind of isotropic material.

\section{Competing Interests}

The authors declare that there are no competing interests regarding the publication of this paper.

\section{Acknowledgments}

This research received specific grant from the Research Foundation of Wuhan Construction Committee and was supported by China Scholarship Council as well.

\section{References}

[1] W. Li, "The study and application of FRP material in concrete structures," Research of Materials Science, vol. 3, no. 1, pp. 17-21, 2014.

[2] H. Karpate, H. Wheat, J. Jirsa, D. Fowler, and D. Whitney, "Repair and rehabilitation of corrosiondamaged concrete elements using FRP composite wraps," World Journal of Engineering, vol. 8, no. 2, pp. 147-150, 2011.
[3] G. Portnov, C. E. Bakis, E. Lackey, and V. Kulakov, "FRP Reinforcing bars-designs and methods of manufacture (Review of Patents)," Mechanics of Composite Materials, vol. 49, no. 4, pp. 381-400, 2013.

[4] A. Prota, G. Manfredi, and F. P. Nardone, "Assessment of design formulas for in-plane FRP strengthening of masonry walls," Journal of Composites for Construction, vol. 12, no. 6, pp. 643649, 2008.

[5] S. S. Pendhari, T. Kant, and Y. M. Desai, "Application of polymer composites in civil construction: a general review," Composite Structures, vol. 84, no. 2, pp. 114-124, 2008.

[6] J. G. Teng, H. Yuan, and J. F. Chen, "FRP-to-concrete interfaces between two adjacent cracks: theoretical model for debonding failure," International Journal of Solids and Structures, vol. 43, no. 18-19, pp. 5750-5778, 2006.

[7] B. Ferracuti, M. Savoia, and C. Mazzotti, "Interface law for FRPconcrete delamination," Composite Structures, vol. 80, no. 4, pp. 523-531, 2007.

[8] C. Mazzotti and M. Savoia, "FRP-Concrete bond behaviour under cyclic debonding force," Advances in Structural Engineering, vol. 12, no. 6, pp. 771-780, 2009.

[9] H. C. Biscaia, I. S. Borba, C. Silva, and C. Chastre, "A nonlinear analytical model to predict the full-range debonding process of FRP-to-parent material interfaces free of any mechanical anchorage devices," Composite Structures, vol. 138, pp. 52-63, 2016.

[10] H. W. Zhang, S. T. Smith, and R. J. Gravina, "Analysis of FRP-to-concrete interfaces using a displacement driven partial interaction model," International Journal of Mechanical Sciences, vol. 117, pp. 210-217, 2016.

[11] T. Xu, Z. J. He, C. A. Tang, W. C. Zhu, and P. G. Ranjith, "Finite element analysis of width effect in interface debonding of FRP plate bonded to concrete," Finite Elements in Analysis and Design, vol. 93, pp. 30-41, 2015.

[12] M. Coelho, A. Caggiano, J. Sena-Cruz, and L. Neves, "Fracturebased interface model for NSM FRP systems in concrete," Composite Structures, vol. 152, pp. 816-828, 2016.

[13] H. C. Biscaia, D. Cruz, and C. Chastre, "Analysis of the debonding process of CFRP-to-timber interfaces," Construction and Building Materials, vol. 113, pp. 96-112, 2016.

[14] S. F. Breña and G. N. McGuirk, "Advances on the behavior characterization of FRP-Anchored Carbon Fiber-Reinforced Polymer (CFRP) sheets used to strengthen concrete elements," International Journal of Concrete Structures and Materials, vol. 7, no. 1, pp. 3-16, 2013.

[15] S. C. Chin, N. Shafiq, and M. F. Nuruddin, "FRP as strengthening material for Reinforced Concrete beams with openings-a review," KSCE Journal of Civil Engineering, vol. 19, no. 1, pp. 213219, 2014

[16] W.-W. Wang, J.-G. Dai, and K. A. Harries, "Performance evaluation of RC beams strengthened with an externally bonded FRP system under simulated vehicle loads," Journal of Bridge Engineering, vol. 18, no. 1, pp. 76-82, 2013.

[17] S. S. Mahini and H. R. Ronagh, "Strength and ductility of FRP web-bonded RC beams for the assessment of retrofitted beamcolumn joints," Composite Structures, vol. 92, no. 6, pp. 13251332, 2010.

[18] K. Amin, "Investigation on the effects of L-shaped FRPs for strengthening of exterior RC joints to relocate the plastic hinge place away from the column face," International Journal of Advances in Engineering Sciences, vol. 3, no. 2, pp. 13-18, 2013. 
[19] Z. Yang and C. Wu, "Analysis on the seismic performance of RC frame beam-column joints strengthened by sprayed FRP," Applied Mechanics and Materials, vol. 578-579, pp. 835-838, 2014.

[20] P. Agarwal, A. Gupta, and R. G. Angadi, "Effect of FRP wrapping on axial behavior of concrete and cyclic behavior of external RC beam column joints," KSCE Journal of Civil Engineering, vol. 18, no. 2, pp. 566-573, 2014.

[21] A. Bossio, F. Fabbrocino, G. P. Lignola, A. Prota, and G. Manfredi, "Simplified model for strengthening design of beamcolumn internal joints in reinforced concrete frames," Polymers, vol. 7, no. 9, pp. 1732-1754, 2015.

[22] E. Z. Beydokhty and H. Shariatmadar, "Behavior of damaged exterior RC beam-column joints strengthened by CFRP composites," Latin American Journal of Solids and Structures, vol. 13, no. 5, pp. 880-896, 2016.

[23] H. K. Lee, "Effectiveness of anchorage in concrete beams retrofitted with sprayed fiber-reinforced polymers," Journal of Reinforced Plastics and Composites, vol. 23, no. 12, pp. 1285-1300, 2004.

[24] A. J. Boyd, Rehabilitation of reinforced concrete beams with sprayed glass giber reinforced polymers [Ph.D. thesis], University of British Columbia, British Columbia, Canada, 2000.

[25] H. K. Lee and L. R. Hausmann, "Structural repair and strengthening of damaged RC beams with sprayed FRP," Composite Structures, vol. 63, no. 2, pp. 201-209, 2004.

[26] S. M. Soleimani, Sprayed glass fibre reinforced polymers in shear strengthening and enhancement of impact resistance of reinforced concrete beams [Ph.D. thesis], University of British Columbia, Vancouver, Canada, 2006.

[27] A. J. Boyd, N. F. Liang, P. S. Green, and K. Lammert, "Sprayed FRP repair of simulated impact in prestressed concrete girders," Construction and Building Materials, vol. 22, no. 3, pp. 411-416, 2008.

[28] S. K. Ha, S. Na, and H. K. Lee, "Bond characteristics of sprayed FRP composites bonded to concrete substrate considering various concrete surface conditions," Composite Structures, vol. 100, pp. 270-279, 2013.

[29] GB/T 1447, Fiber-Reinforced Plastics Composites- Determination of Tensile Properties, 2005.

[30] K. S. Lee, "A seismic strengthening technique for reinforced concrete columns using Sprayed FRP," Journal of Advanced Concrete Technology, vol. 10, pp. 219-230, 2012. 

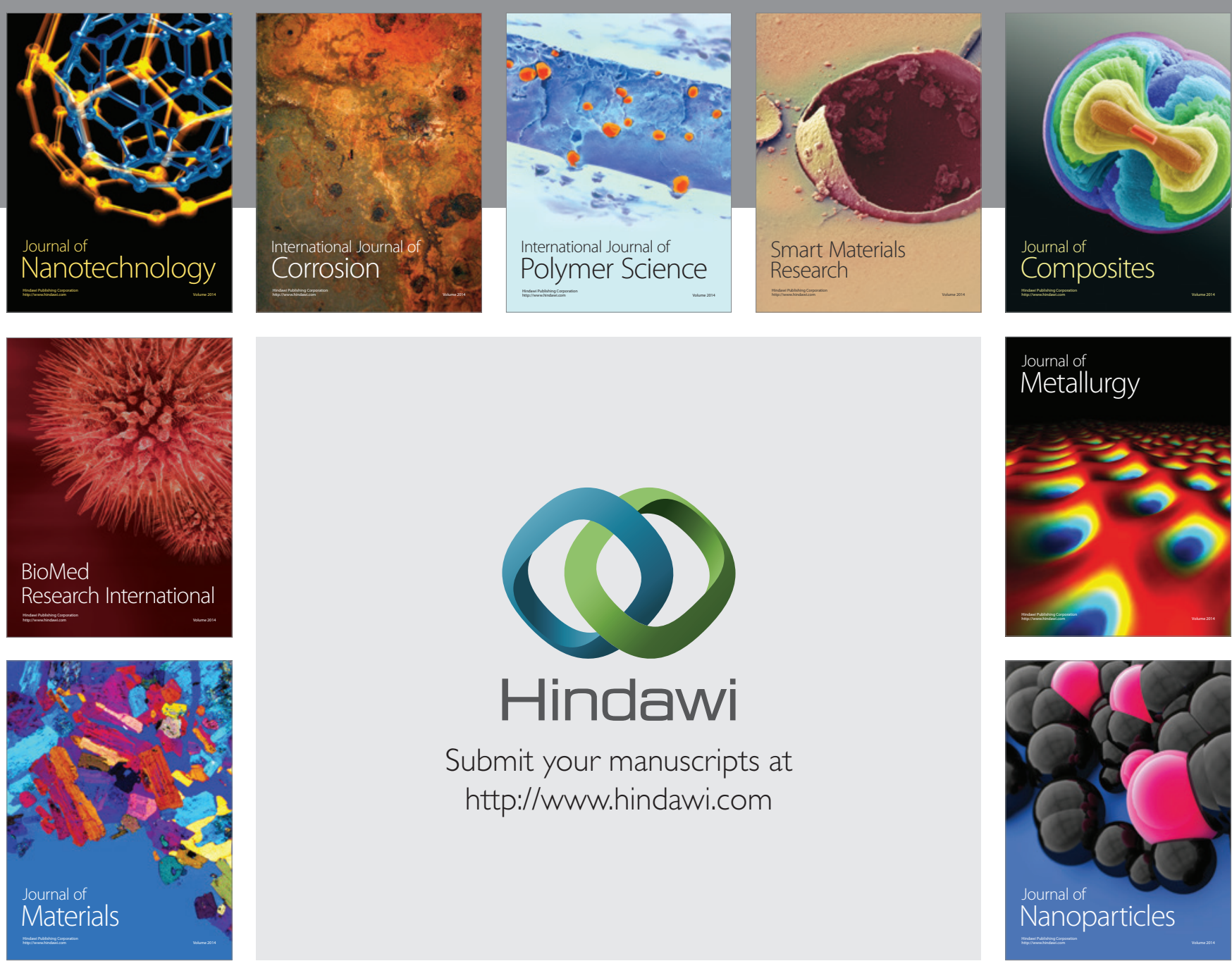

\section{Hindawi}

Submit your manuscripts at

http://www.hindawi.com

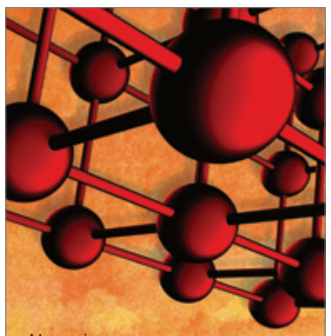

Materials Science and Engineering
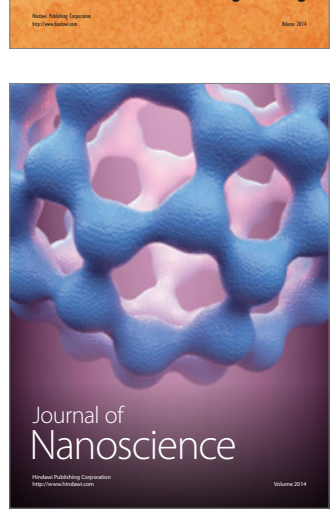
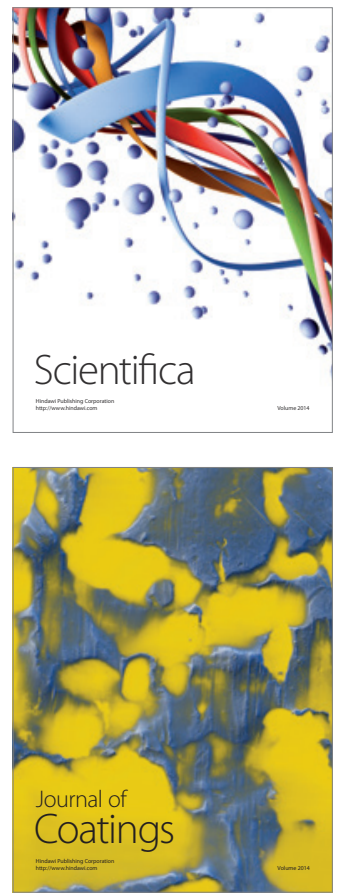
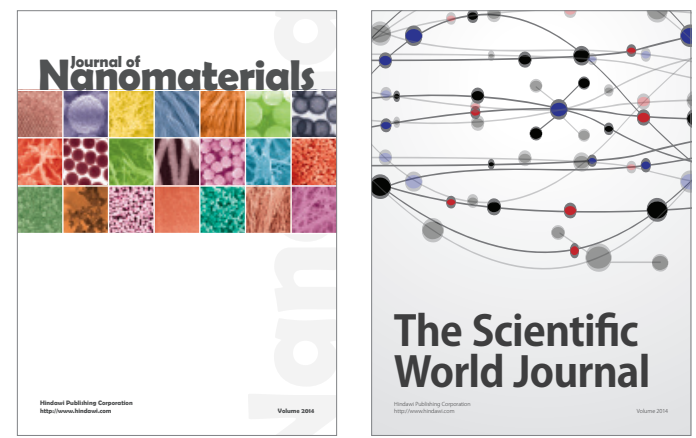

The Scientific World Journal
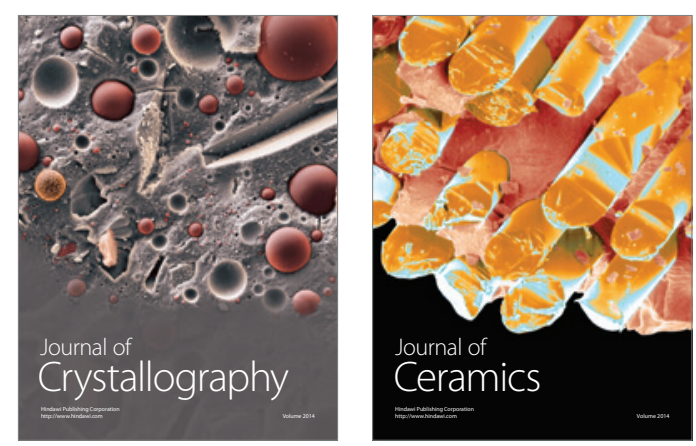
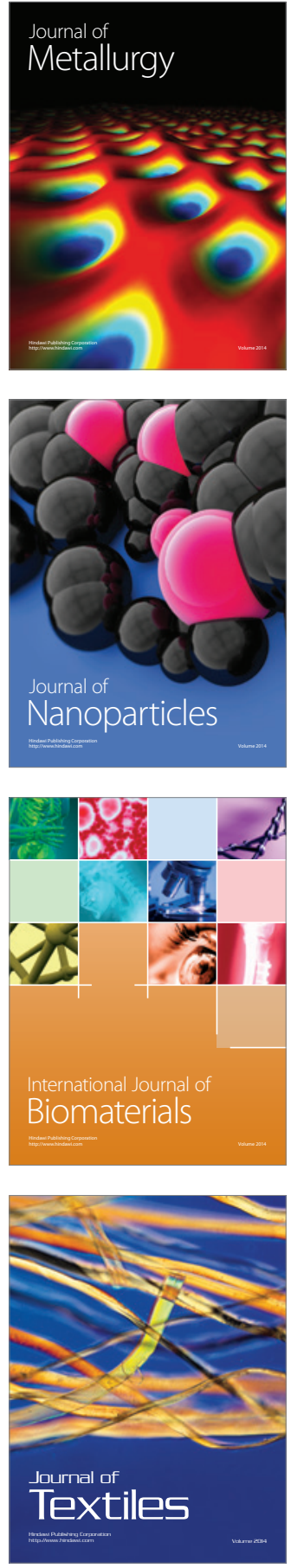